\title{
Faktor Risiko Kejadian Diabetes Melitus pada Akseptor Pengguna Kontrasepsi Oral
}

Nurmainah*, Rafli Armandani, Mohammad Andrie

Program Studi Farmasi, Fakultas Kedokteran, Universitas Tanjungpura, Pontianak, Indonesia

*Corresponding author: nurmainah@pharm.untan.ac.id

Submitted: 11 Februari 2020

Accepted: 19 Mei 2020

Published: 30 November 2020

\begin{abstract}
Background: Hormone progesterone in oral contraceptives can interfere with carbohydrate metabolism and accumulation of fat levels are at risk for an increase in blood sugar levels. Objective: We studied the association between types of contraception and the value of the Body Mass Index (BMI) to the risk of diabetes mellitus in acceptors in the Perumnas II Pontianak Public Health Care. Methods: The research method used observational with cross sectional design. Data collection using medical record acceptors during the period January 2018 to March 2019. The sampling technique was done by purposive sampling, based on inclusion and exclusion criteria. There were 44 acceptors who fulfilled the inclusion and exclusion criteria in this study. Futhermore, the measurement of blood sugar levels while using a glucometer. The data obtained were analyzed by chi-square test. Results: The results showed that 20\% of the acceptors used single oral contraceptives and $80 \%$ were combined. However, the difference in the risk of diabetes mellitus from the two groups was not statistically significant ( $p=0.647 ;$ OR $=0.44 ; C I 95 \%=0.45$ - 4.395). In addition, acceptors with a BMI value $\geq 23\left(\mathrm{Kg} / \mathrm{m}^{2}\right)$ were $60 \%$ and acceptors with a BMI value $<23\left(\mathrm{Kg} / \mathrm{m}^{2}\right)$ were $40 \%$. However, the difference in the risk of diabetes mellitus between the two groups was not statistically significant $(p=0.30 ; \mathrm{OR}=3.8 ; \mathrm{CI95 \%}=0.560$ 26.052). Conclusion: There is no significant associated between the oral contraceptives and BMI to the risk of the incidence of diabetes mellitus.
\end{abstract}

Keywords: acceptor, body mass index, diabetes mellitus, oral contraceptives

\begin{abstract}
Abstrak
Pendahuluan: Kandungan hormon progesteron dalam kontrasepsi oral dapat menggangu metabolisme karbohidrat dan penumpukkan kadar lemak yang berisiko untuk terjadinya peningkatan kadar gula darah. Tujuan: Tujuan penelitian ini adalah untuk menganalisis hubungan jenis kontrasepsi dan nilai Indeks Masa Tubuh (IMT) terhadap risiko kejadian diabetes melitus pada akseptor kontrasepsi oral di Puskesmas Perumnas II Pontianak. Metode: Metode penelitian observasional dengan rancangan potong lintang yang bersifat analitik. Pengumpulan data dilakukan secara retrospektif berdasarkan data rekam medik akseptor kontrasepsi oral selama periode Januari 2018 hingga Maret 2019. Teknik pengambilan sampel dilakukan secara purposive sampling, berdasarkan kriteria inklusi dan ekslusi. Akseptor yang memenuhi kriteria inklusi dan ekslusi pada penelitian ini sebanyak 44 akseptor. Selanjutnya, 44 akseptor dilakukan pengukuran kadar gula darah sewaktu dengan menggunakan alat glukometer. Data yang diperoleh dianalisis dengan uji khi kuadrat. Hasil: Hasil penelitian menunjukkan bahwa akseptor yang menggunakan kontrasepsi oral tunggal mengalami risiko kejadian diabetes melitus sebanyak $20 \%$ sedangkan akseptor yang menggunakan kontrasepsi oral kombinasi sebanyak $80 \%$. Namun perbedaan risiko kejadian diabetes melitus dari kedua kelompok secara statistik tidak bermakna signifikan ( $p=0,647$; OR $=0,44 ;$ CI 95\% $=0,45-4,395)$. Selain itu, akseptor kontrasepsi oral dengan nilai IMT $\geq 23\left(\mathrm{Kg} / \mathrm{m}^{2}\right)$ yang mengalami risiko kejadian diabetes melitus tercatat sebanyak $60 \%$ dan akseptor dengan nilai
\end{abstract}


IMT $<23\left(\mathrm{Kg} / \mathrm{m}^{2}\right)$ sebanyak 40\%. Namun perbedaan risiko kejadian diabetes melitus kedua kelompok secara statistik tidak bermakna signifikan ( $p=0,30$; OR $=3,8$; CI95\% $=0,560-26,052)$. Kesimpulan: Tidak terdapat hubungan yang bermakna signifikan antara jenis kontrasepsi oral dan IMT terhadap risiko kejadian diabetes melitus pada akseptor pengguna kontrasepsi oral.

Kata kunci: akseptor, diabetes melitus, indeks masa tubuh, kontrasepsi oral

\section{PENDAHULUAN}

Program Keluarga Berencana (KB) telah diakui mampu menekan angka kelahiran di Indonesia. Hasil Total Fertility Rate (TFR) di Indonesia dari tahun 2012 hingga tahun 2017 diketahui telah mengalami penurunan dari 2,6\% menjadi 2,4\%. Hal ini diimbangi dengan persentase wanita kawin yang telah mengikuti program KB di Indonesia sekitar 63\% dimana 57\% menggunakan program $\mathrm{KB}$ dengan metode modern dan sisanya menggunakan metode KB tradisional. Salah satu metode $\mathrm{KB}$ modern yang banyak dipilih oleh wanita kawin atau akseptor adalah kontrasepsi oral (pil KB) setelah KB suntik (BKKBN, 2018).

Kontrasepsi oral merupakan salah satu kontrasepsi hormonal diketahui memiliki reversibilitas yang tinggi dibandingkan dengan kontrasepsi hormonal lainnya. Namun demikian, penggunan kontrasepsi oral dapat menimbulkan efek samping berupa peningkatan kadar gula darah. Risiko diabetes melitus pada wanita kawin yang menggunakan kontrasepsi oral 4 kali lebih besar dibandingkan wanita kawin yang tidak menggunakan kontrasepsi oral (Sudoyo, 2009; Deleskog dkk., 2011). Akseptor kontrasepsi oral yang mengalami peningkatan gula darah diperkirakan sekitar $10 \%$ hingga 20\% (Nurpalah, 2018; Rahma dkk., 2019)

Jenis kontrasepsi oral ada dua yaitu kontrasepsi oral tunggal yang mengandung progesteron saja dan kontrasepsi oral kombinasi yang mengandung progesteron dan esterogen sintetik. Adanya kandungan hormon progesteron dalam kontrasepsi oral tersebut diketahui dapat menggangu metabolisme karbohidrat melalui pergeseran kortisol oleh progestin dari ikatan globulin. Globulin diketahui memiliki afinitas yang tinggi untuk berikatan dengan progesteron dibandingkan dengan kortisol. Kondisi ini menyebabkan terjadi peningkatan kadar kortisol bebas dari proses metabolisme glukosa (glukogenesis) yang berdampak pada peningkatan kadar gula darah. Di sisi lain, adanya gangguan metabolisme karbohidrat dari penggunaan kontrasepsi oral maka diduga berdampak pada peningkatan berat badan akseptor (Speroff \& Fritz, 2005). Peningkatan berat badan pada akseptor mencapai 5\% atau lebih selama kurun waktu 6 bulan, sekitar $2 \mathrm{Kg}$ setelah 12 bulan, dan terus meningkat hingga $10 \mathrm{Kg}$ setelah pemakaian 24 bulan (Bonny dkk., 2009). Progesteron sintetik berpotensi untuk terjadinya penumpukan lemak di bawah kulit dan meningkatkan akumulasi lemak viseral yang disebabkan kadar estrogen pada akseptor yang menggunakan kontrasepsi oral rendah atau mengalami hipoestrogen (Reifsnider dkk., 2013). Kondisi tersebut memicu untuk berkembangnya penyakit diabetes melitus (DM) tipe 2 pada akseptor pengguna kontrasepsi oral.

Berdasarkan permasalahan tersebut peneliti tertarik untuk menganalisis hubungan peningkatan kadar gula darah pada akseptor pengguna kontrasepsi oral berdasarkan jenis kontrasepsi oral dan indek masa tubuh (IMT) akseptor. Penelitian dilakukan pada akseptor yang menggunakan kontrasepsi oral di Puskesmas Perumnas II Pontianak. Jumlah akseptor KB aktif di Puskesmas Perumnas II merupakan akseptor terbanyak di kota Pontianak. Jumlah akseptor yang tercatat di Puskesmas tersebut sebanyak 6.864 jiwa, dimana $28,63 \%$ menggunakan kontrasepsi oral.

\section{BAHAN DAN METODE Bahan}

Bahan yang digunakan dalam penelitian ini adalah data rekam medik yang memuat data karakteristik akspetor seperti usia, jenis kontrasepsi oral, berat badan, tinggi badan, dan kadar gula darah sewaktu.

Alat

Alat yang digunakan dalam penelitian ini adalah lembar pengumpul data, program SPSS (Statistical Product and Service Solutions) versi 23.0.0, dan alat pengukur kadar gula darah atau glucometer (Gluco $\left.\mathrm{dr}^{\circledR}\right)$.

Metode penelitian dan teknik pengambilan sampel

Metode penelitian yang digunakan dalam penelitian ini adalah observasional dengan rancangan potong lintang (cross sectional) yang bersifat analitik. Pengumpulan data secara retrospektif menggunakan data rekam medik akseptor kontrasepsi oral selama periode Januari 2018 hingga Maret 2019. Teknik 
pengambilan sampel dilakukan secara purposive sampling, yaitu pengambilan sampel berdasarkan pada pemenuhan kriteria yang telah ditentukan sebelumnya (Riwidikno \& Handoko, 2012). Kriteria inklusi dalam penelitian ini yaitu, wanita berusia 19 tahun atau lebih yang menggunakan kontrasepsi oral tunggal maupun kombinasi, tidak menggunakan obat diabetes melitus maupun insulin, dan tidak memiliki riwayat diabetes mellitus. Kriteria eksklusinya adalah memiliki catatan data rekam medik yang tidak lengkap atau tidak jelas terbaca. Akseptor yang memenuhi kriteria inklusi dan ekslusi pada penelitian ini sebanyak 44 akseptor. Selanjutnya, 44 akseptor dilakukan pengukuran kadar gula darah sewaktu. Pengambilan sampel darah yang digunakan adalah sampel darah perifer di ujung jari dan pengukuran kadar gula darah dilakukan dengan menggunakan alat glukometer. Data yang diperoleh dianalisis dengan menggunakan uji khi kuadrat (chisquare). Uji dilakukan untuk mengetahui hubungan antara variabel jenis kontrasepsi oral dan IMT dengan peningkatan kadar gula darah akseptor (Dahlan, 2009).

\section{HASIL DAN PEMBAHASAN}

Setelah dilakukan observasi data akseptor yang menggunakan kontrasepsi oral selama 1 tahun hingga lebih terlihat karakteristik akseptor pada Tabel 1, dimana akseptor yang menggunakan kontrasepsi oral sebanyak 70,45\% berusia di bawah 40 tahun. Akseptor dengan usia tersebut memiliki masa reproduksi yang sehat dan subur sehingga kontrasepsi oral digunakan sebagai cara untuk menjarangkan kehamilan (Meysetri dkk., 2019). Jenis kontrasepsi oral yang banyak dipilih oleh akseptor adalah kontrasepsi oral kombinasi sebanyak $65,91 \%$. Kontrasepsi oral kombinasi yang digunakan akseptor mengandung levonorgestel 0,15 $\mathrm{mg}$ dan ethinylestradiol $0,03 \mathrm{mg}$. Kontrasepsi oral kombinasi memiliki efektivitas yang sama dengan tubektomi dalam mencegah kehamilan (Baziad, 2002). Akseptor yang memiliki IMT $\geq 23 \mathrm{Kg} / \mathrm{m}^{2}$ sebanyak $31,82 \%$. Nilai IMT $\geq 23 \mathrm{Kg} / \mathrm{m}^{2}$ menunjukkan akseptor berada pada derajat risiko obesitas. Obesitas merupakan salah satu faktor penyebab terjadinya diabetes melitus tipe 2 (PERKENI, 2015).

Tabel 1. Karakteristik akseptor di Puskesmas Perumnas II $(\mathrm{n}=44)$

\begin{tabular}{|c|c|c|c|}
\hline No. & Karakteristik & Jumlah & Persentase $(\%)$ \\
\hline \multirow{3}{*}{1.} & Jenis Kontrasepsi oral & & \\
\hline & a. Tunggal & 15 & 30,09 \\
\hline & b. Kombinasi & 29 & 65,91 \\
\hline \multirow{3}{*}{2.} & $\begin{array}{l}\text { Indeks Masa Tubuh } \\
\left(\mathrm{Kg} / \mathrm{m}^{2}\right)\end{array}$ & & \\
\hline & a. $\geq 23$ & 14 & 31,82 \\
\hline & b. $<23$ & 30 & 68,18 \\
\hline \multirow{4}{*}{3.} & $\begin{array}{l}\text { Kadar gula darah } \\
\text { sewaktu (mg/dL) }\end{array}$ & & \\
\hline & a. $>140$ & 5 & 11,36 \\
\hline & b. $<140$ & 39 & 88,64 \\
\hline & Total & 44 & 100 \\
\hline
\end{tabular}

Tampak pada Tabel 2 bahwa akseptor kontrasepsi oral yang menggunakan kontrasepsi oral tunggal yang mengalami risiko kejadian diabetes melitus sebanyak $20 \%$ dan akseptor kontrasepsi oral kombinasi yang mengalami risiko kejadian diabetes melitus sebanyak $80 \%$. Namun perbedaan risiko diabetes melitus dari kedua kelompok secara statistik tidak memiliki hubungan yang bermakna signifikan ( $p=0,647$; OR = 0,44; CI95\% = 0,45 - 4,395). Artinya, dari hasil analisis ini menunjukkan tidak ada hubungan antara akseptor yang menggunakan kontrasepsi oral tunggal maupun kontrasepsi oral kombinasi dengan risiko kejadian diabetes melitus (Meysetri dkk., 2019). Secara teori, kontrasepsi oral tunggal yang mengandung progesteron memiliki risiko lebih besar dibandingkan dengan kontrasepsi oral kombinasi yang mengandung progesteron dan esterogen. Hormon progesteron cenderung dapat meningkatkan kadar gula darah sedangkan hormon esterogen dapat menstabilkan kadar gula darah (Rahma dkk., 2019). Pada umumnya akseptor yang menggunakan kontrasepsi oral kombinasi memiliki kadar gula darah sewaktu yang normal (Rahma dkk., 2019). Kontrasepsi oral kombinasi tidak mengganggu metabolisme karbohidrat, hanya sebagian kecil saja yang mengalami gangguan, tetapi tidak sampai mengalami gangguan klinis yang bermakna (Bender \& Mayes, 2009). 
Tabel 2. Hubungan jenis kontrasepsi oral dengan risiko kejadian diabetes melitus

\begin{tabular}{|c|c|c|c|c|c|c|c|}
\hline \multirow{3}{*}{ Jenis Kontrasepsi Oral } & \multicolumn{4}{|c|}{$\begin{array}{l}\text { Risiko Kejadian } \\
\text { Diabetes Melitus }\end{array}$} & \multirow{3}{*}{$p$-value } & \multirow{3}{*}{ OR } & CI $95 \%$ \\
\hline & \multicolumn{2}{|c|}{$\mathrm{Ya}$} & \multicolumn{2}{|c|}{ Tidak } & & & \multirow{2}{*}{ Lower-Upper } \\
\hline & $\mathrm{n}$ & $\%$ & $\mathrm{n}$ & $\%$ & & & \\
\hline Tunggal & 1 & 20 & 14 & 35,9 & & ref & \\
\hline Kombinasi & 4 & 80 & 25 & 64,1 & 0,647 & 0,44 & $0,45-4,395$ \\
\hline
\end{tabular}

Keterangan: ref: reference (pembanding); OR: odds ratio; CI: confidence interval

Tampak pada Tabel 3 bahwa akseptor kontrasepsi oral dengan nilai IMT $\geq 23\left(\mathrm{Kg} / \mathrm{m}^{2}\right)$ yang mengalami risiko kejadian diabetes melitus sebayak $60 \%$ dan akseptor dengan nilai IMT $<23\left(\mathrm{Kg} / \mathrm{m}^{2}\right)$ yang mengalami risiko kejadian diabetes melitus sebanyak $40 \%$. Namun perbedaan risiko diabetes melitus kedua kelompok secara statistik tidak memiliki hubungan yang bermakna signifikan ( $p=0,30$; OR $=3,8$; CI95\% $=0,560-26,052)$. Artinya, tidak ada hubungan antara akseptor yang memiliki IMT $\geq 23\left(\mathrm{Kg} / \mathrm{m}^{2}\right)$ maupun akseptor yang memiliki IMT $<23\left(\mathrm{Kg} / \mathrm{m}^{2}\right)$ dengan risiko kejadian diabetes melitus (Arif, 2014). Hal ini dikarenakan pengukuran risiko diabetes melitus belum cukup dengan hanya mengukur nilai IMT saja, tetapi perlu dilakukan pengukuran lingkar pinggang (Adwinda \& Srimiati, 2019). Seperti halnya yang dilakukan di negara Australia, Thailand, dan Hongkong (Pongastha dkk., 2012). Hasil pengukuran lingkar pinggang dapat digunakan sebagai prediksi yang lebih baik untuk mengukur resistensi insulin pada DM tipe 2 dibanding dengan nilai IMT. Hal ini dikarenakan IMT dapat dipengaruhi oleh beberapa faktor seperti kepadatan tulang dan otot (Huang dkk., 2012). Penelitian lainnya menyebutkan bahwa peningkatan IMT dengan kadar gula darah puasa memiliki hubungan bermakna hanya sampai kadar gula darah 110 mg/dL (Kang \& Kim, 2012).

Tabel 3. Hubungan Indeks Masa Tubuh (IMT) dengan Risiko Kejadian Diabetes Melitus

\begin{tabular}{|c|c|c|c|c|c|c|c|}
\hline \multirow{3}{*}{ IMT $\left(\mathrm{Kg} / \mathrm{m}^{2}\right)$} & \multicolumn{4}{|c|}{$\begin{array}{l}\text { Risiko Kejadian } \\
\text { Diabetes Melitus }\end{array}$} & \multirow{3}{*}{$p$-value } & \multirow{3}{*}{ OR } & CI 95\% \\
\hline & \multicolumn{2}{|c|}{$\mathrm{Ya}$} & \multicolumn{2}{|c|}{ Tidak } & & & \multirow{2}{*}{ Lower-Upper } \\
\hline & $\mathrm{n}$ & $\%$ & $\mathrm{n}$ & $\%$ & & & \\
\hline$\geq 23$ & 3 & 60 & 11 & 28,2 & \multirow{2}{*}{0,30} & $r e f$ & \\
\hline$<23$ & 2 & 40 & 28 & 71,8 & & 3,8 & $0,560-26,052$ \\
\hline
\end{tabular}

Keterangan: ref: reference (pembanding); OR: odds ratio; CI: confidence interval

\section{KESIMPULAN}

Kesimpulan dari penelitian bahwa tidak terdapat hubungan yang signifikan antara jenis kontrasepsi oral dan nilai IMT dengan risiko kejadian diabetes melitus pada akseptor pengguna kontrasepsi oral di Puskesmas Perumnas II Pontianak, dimana nilai satatistiknya secara berturut-turut menunjukkan $p=0,647$; OR $=$ 0,$44 ;$ CI95\% $=0,45-4,395$ dan $p=0,30 ;$ OR $=3,8$; $\mathrm{CI} 95 \%=0,560-26,052$.

\section{UCAPAN TERIMAKASIH}

Terima kasih kami ucapkan kepada Program Studi Farmasi Fakultas Kedokteran Universitas Tanjungpura dan pihak Puskesmas Perumnas II Pontianak yang telah membantu selama pelaksanaan penelitian.

\section{DAFTAR PUSTAKA}

Adwinda, M. D. \& Srimiati, M. (2019). Hubungan Lingkar Perut, Konsumsi Gula dan Lemak dengan Kadar Glukosa Darah Pegawai Direkotrat Poltekkes Kemenkes Jakarta II. Nutrire Diaita; 11; 7-17.

Arif, Y. E. D. R. (2014). Hubungan Indeks Massa Tubuh dengan Kadar Gula Darah Puasa pada Pegawai Sekretariat Daerah Provinsi Riau. Jurnal Kesehatan Masyarakat; 1; 14-15.

Baziad, A. (2002) Kontrasepsi Hormonal. Jakarta: Yayasan Bina Pustaka Sarwono Prawirohardjo.

Bender, D. \& Mayes, P. (2009). Gluconeogenesis \& Control of Blood Glucose. Jakarta: Buku Kedokteran EGC. 
BKKBN. (2018). Survey Demografi dan Kesehatan Indonesia by BKKBN. http://sdki.bkkbn.go.id/?lang=id. Accessed: 10 September 2019.

Bonny, A., Secic, M. \& Cromes, B. (2009). A Longitudinal Comparison of Body Composition Changes in Adolescent Girls Receiving Hormonal Contraception. Jounal of Adolescent Health; 45; 423-425.

Dahlan, M. (2009). Statistik untuk Kedokteran dan Kesehatan (4th ed.). Jakarta: Salemba Medika.

Deleskog, A., Hilding, A. \& Östenson, C. G. (2011) Oral Contraceptive Use and Abnormal Glucose Regulation in Swedish Middle Aged Women. Diabetes Research and Clinical Practice; 92; 288-292.

Huang, L. H., Liao, Y. L. \& Hsu, C. H. (2012). Waist Circumference is a Better Predictor Than Body Mass Index of Insulin Resistance in Type 2 Diabetes. Obesity Research and Clinical Practice; 6; e314-e320.

Kang, H. M. \& Kim, D. J. (2012). Body Mass Index and Waist Circumference According to Glucose Tolerance Status in Korea: The 2005 Korean Health and Nutrition Examination Survey. Journal of Korean Medical Science; 27; 518524.

Meysetri, F. R., Serudji, J. \& Agus, M. (2019). Perbedaan Kadar Glukosa Darah Puasa pada Akseptor Suntik Depo Medroksi Progesteron Asetat dengan Akseptor Pil Kombinasi di
Puskesmas Lubuk Buaya Padang Tahun 2018. Jurnal Kesehatan Andalas; 8; 227.

Nurpalah, R. (2018). Pemeriksaan Glukosa Darah pada Wanita Pengguna Kontrasepsi Oral dan pada Wanita Hamil Trimester III. Jurnal Kesehatan Bakti Tunas Husada; 17; 385-389.

PERKENI. (2015). Pengolahan dan Pencegahan Diabetes Melitus Tipe 2 di Indonesia. Jakarta: PB PERKENI.

Pongastha, S., Morakot, N., Sangchun, K. \& Chaovisitsaree, S. (2012). Correlation Between Waist Circumference and Other Factors in Menopausal Women In Thailand. Health; 4; 6065.

Rahma, S., Mursyida, A. \& Rauf, Y. (2019). Kadar Gula Darah Pengguna Kontrasepsi Hormonal. Jambura Nursing Journal; 1; 73-84.

Reifsnider, E., Mendias, N., Davila, Y. \& Babendure, J. B. (2013). Contraception and the Obese Woman. Journal of the American Association of Nurse Practitioners; 25; 223-233.

Riwidikno \& Handoko. (2012). Statistik Kesehatan. Yogyakarta: Mitra Cendikia.

Speroff, L. \& Fritz, M. (2005). Hormone Biosynthesis, Metabolism and Mechanism of Action in Clinical Gynecologic Endocrinology and Infertility. Lippincot Williams dan Wilkin; 7; 87-94.

Sudoyo. (2009). Buku Ajaran Ilmu Penyakit Dalam. Jakarta: Interna Publishing. 